2

\title{
Application-specific oxide-based and metal-dielectric thin film materials prepared by RF magnetron sputtering
}

\author{
Mohammad Nur-E-Alam *, Wade Lonsdale, Mikhail Vasiliev, and Kamal Alameh \\ Electron Science Research Institute, School of Science, Edith Cowan University, 270 Joondalup Drive, \\ Joondalup 6027, WA, Australia.; E-mails: m.nur-e-alam@ecu.edu.au (M.N.A), m.vasiliev@ecu.edu.au \\ (M.V), w.lonsdale@ecu.edu.au (W.L) and k.alameh@ecu.edu.au (K.A) \\ * Correspondence: m.nur-e-alam@ecu.edu.au
}

\begin{abstract}
We report on the development of several different thin-film functional material systems prepared by RF magnetron sputtering at Edith Cowan University nanofabrication labs. We conduct research on the design, prototyping, and practical fabrication of high-performance magneto-optic (MO) materials, oxide based sensor components, and heat regulation coatings for advanced construction and solar windows.
\end{abstract}

Keywords: thin films; coatings; magneto-optics; sensors; glass; heat regulation.

\section{Introduction}

Among all the physical vapor deposition techniques, magnetron sputter deposition is one of the most common technologies used to grow thin film materials and coatings for various existing and modern nano-technological applications. Sputter deposition of thin films has a long track record of development history in vacuum technology since 1800s [1-10]. Many dedicated research groups and scholars were involved in the development of the modern phase of magnetron sputtering technology, although the journey of the magnetron sputtering process is still considered far from its ultimate development $[6,8]$. However, nowadays the magnetron sputtering is considered one of the most effective processes for the deposition of a wide range of high-quality thin-film materials either in single or multilayer form, including metals, dielectrics, metal oxides of complex stoichiometry, and nanoparticles. A vast number of sputtered material types were shown to be suitable for various existing and emerging nanotechnology-related applications, and attractive for many rapidly growing diverse market sectors. Sputtering processes allow to deposit thin-film materials either on bare substrates or on top of any structured systems, e.g. photonic or magneto-photonic crystals, usually without having any unpredictable thickness uniformity or stoichiometry issues with the grown films. Thin-film materials, especially radio frequency (RF) magnetron sputtered thin films were originally considered useful mainly in electronics and semiconductor devices, however, sputtered thin films have also been found to be applicable within a wide range of fields such as optoelectronics, energy, mechanical/chemical, optical coatings, life sciences, and others [9-29]. In this nano-technological era, the sputter-deposition of thin films becomes a rather ubiquitous and actively growing field of human endeavour, integrating the fundamental and important scientific areas of research, process development, deposition-system design, and new product manufacturing. This trend is expected to continue into the periods extending far into the foreseeable future. The reasons behind the rapid growth of the sputtering industry over other thin film manufacture techniques include (i) possibility of using large-area sputtering targets that provide uniform film thickness over large-area substrates; (ii) flexibility of growing thin or extremely ultra-thin film materials of various composition types (even complex stoichiometry types, e.g. oxide-mix-based iron garnet precursors) on different substrate types; (iii) ease of controlling the film thickness by calibrating the deposition run times and 
other parameters; (iv) better layer-to-substrate adhesion quality, compared to techniques such as thermal evaporation. Also, the successful establishment of deposition technologies for thin polymer films and metal/plasma polymer nano-particles fabrication using polymer or metal-polymer composite targets in RF magnetron sputtering systems by optimizing the process gas chemistries (e.g. argon, nitrogen), shows the diversity of thin-film types grown by RF magnetron sputtering [30-33]. Figure 1 presents a wide range of possible application areas of sputtered thin films for the continued exploration by future generations.

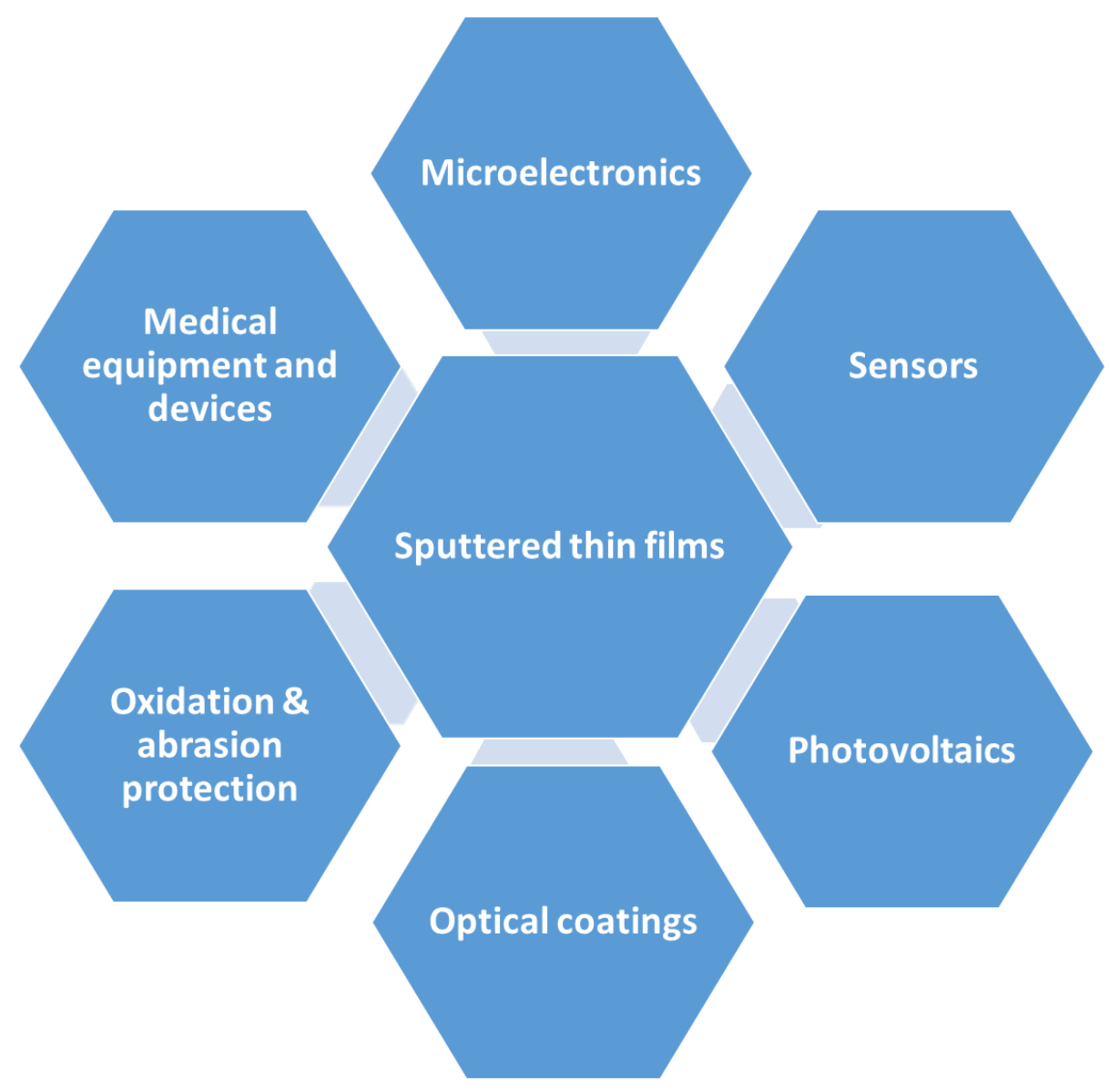

Figure 1. Spectrum of modern nano-technological application areas reliant on sputtered thin-film materials.

Based on the current and possible future emerging applications, the global market of sputtered thin films can be subdivided into many segments. According to the report [34] made by PR Newswire in 2017, the sputtered thin films market volume including sputtering-related equipment, raw materials, and services, amounts to approximately one-quarter of the total estimated (over US $\$ 70$ billion) value of global markets of thin-film technologies in 2016, and is expected to grow at a significant rate. However, according to the MarketWatch report published in 2018, the thin film materials market is expected to witness a substantial growth from 2018 to 2024, due to the demand for miniaturization of thin-film related technologies, devices, and products. In addition, the increasing number of applications and end-use industry practices are also expected to propel the growth of the thin-films product markets in the near future [35].

In this paper, we discuss the experimental results selected from a decade-long lab-based work, during which the RF sputtering synthesis of different thin-film material types and multilayer structures have been explored extensively. We also present and discuss the specific material development results and functional material properties of interest for several specific applications. The organization of the article is as follows. Section 2 introduces the background study of Bisubstituted iron garnet thin-film materials and multilayers together with some very recently obtained 
optical properties for highly bismuth-substituted iron garnets of composition type $\mathrm{Bi}_{2} \mathrm{Dy}_{1} \mathrm{Fe}_{4} \mathrm{Ga}_{1} \mathrm{O}_{12}$ (BiDyIG). These garnet composition types (with bismuth substitution levels above about 1.8) can only be prepared using physical vapour deposition techniques (e.g. sputtering), and have not been reported synthesized by crystal growth techniques such as liquid-phase epitaxy. Section 3 describes the design, fabrication and characterization of ruthenium oxide $\left(\mathrm{RuO}_{2}\right)$ thin films grown on rigid and flexible substrates, for sensor applications. Section 4 describes the fabrication techniques and process parameters used for growing metal-dielectric nano-composite (MDC) layers and MDC layers contained within multilayer structures for use in next-generation environment-friendly highly durable optical coatings for solar and thermal radiation control. The optical properties of these MDC thin-films and multilayer building blocks containing nanocomposite-type materials are presented in this section.

\section{Garnets, garnet-oxide composites, and multilayer structures manufactured by sputtering}

Natural garnets are popular as gemstones, but when they are engineered either by modifying their stoichiometry or by adjusting the fabrication process, they can possess extra-ordinary multifunctional properties that make them attractive for various applications e.g. integrated photonic circuits and devices. Through nano-engineering, garnet thin films can be controlled, at the atomic level, to attain naturally-unachievable photonic and magnetic properties that open the way towards the development of magnetophotonic and magneto-plasmonic crystals (MPCs) for a wide range of applications, including telecommunication, biomedicine, digital forensics, sensing and data processing. Thin-film garnets have a long history that started since these were developed in 1960 for the first time for use in bubble memory device applications [36-55]. The properties of thin garnet films are always dependent on their fabrication methods, process parameters and especially on the stoichiometry of the material. By varying the materials compositional constituents together with their optimized fabrication process parameters in RF magnetron sputtering systems, the magnetic and magneto-optic properties of garnet thin films can be tailored for specific applications. Multiple research groups worldwide [56-65] have conducted a significant number of research works using only RF magnetron sputtering to synthesize, develop and improve many garnet thin-film material systems. Since the last decade, a number of highly bismuth (Bi) substituted iron garnet thin-film material systems including garnet-oxide and garnet-garnet nano-composite derivatives, have been synthesized, their sputtering process parameters optimized, and many studies of the optical, magnetic and magneto-optical properties were reported by our group at ECU [66-73]. We have reported obtaining nano-crystalline garnet thin-film materials with high Faraday rotation across the visible spectral range, a record-high magneto-optic quality, very low coercive force with perpendicular magnetization and almost in-plane magnetization types. Also, a rather unconventional magnetic switching properties have recently been demonstrated in all-garnet multilayer thin film structures. In this section, we present the recently obtained results on the optical constants of RF sputtered highly Bi-substituted iron-garnet precursors of nominal composition type $\mathrm{Bi}_{2} \mathrm{Dy}_{1} \mathrm{Fe}_{4} \mathrm{Ga}_{1} \mathrm{O}_{12}$ (BiDyIG) and garnet-oxide composites (GOC), together with a glimpse of the previously bestachieved MO properties in thin garnet films of similar compositions. The unconventional hysteresis loop shapes observed in GOC-based all-garnet multilayer structures are also presented.

Figure 2(a) shows the measured transmission spectra of as-deposited $\mathrm{Bi}_{2} \mathrm{Dy}_{1} \mathrm{Fe}_{4} \mathrm{Ga}_{1} \mathrm{O}_{12}(\mathrm{BiDyIG})$ garnet and $\mathrm{BiDyIG}: \mathrm{Bi}_{2} \mathrm{O}_{3}(17 \& 23.3$ vol. \%) composite thin film layers prepared on glass substrates by using RF magnetron co-sputtering process. These particular garnet types possessed MO garnet compositions (and optical properties) of special importance in common application areas, e.g. Faraday rotators, ferromagnetic resonance-based microwave devices, MPCs, and MO imagers. In the co-sputtering process, two separate oxide-mix-based ceramic targets $\left(\mathrm{Bi}_{2} \mathrm{Dy}_{1} \mathrm{Fe}_{4} \mathrm{Ga}_{1} \mathrm{O}_{12}\right.$, and $\left.\mathrm{Bi}_{2} \mathrm{O}_{3}\right)$ were used and the materials volumetric fraction ratios were controlled and calculated from their partial deposition rates. The details of several GOC layer deposition technologies and sputtering process parameters are described in Refs. [66, 68-70]. From the thickness-dependent transmission- 
124

125

126

127

128

129

130

131

132

133

134

135

136

137

138

139

wave interference fringes intensities (measured over a wide range of wavelengths in all samples, Fig 2a), using a new combinatorial approach, the optical constants of amorphous garnet-precursor layers are calculated and refined, together with the film thickness confirmation [73]. This combinatorial approach employs a custom-built spectrum-fitting software in conjunction with Swanepoel envelop method (SWEM). The following operational steps are conducted for the evaluation of optical constants: (i) calculation of the refractive index data and film thickness using the SWEM method[74]; (ii) use of the calculated index data (from SWEM), in conjunction with least-square fitting to derive the real part of index from Cauchy's formula $\left(n(\lambda)=a+b / \lambda^{2}\right)$; (iii) use of the refractive index data (derived from Cauchy's formula) in magnetic photonic crystal (MPC) analysis software [75] to model and fit the measured transmission spectra, and (iv) from this fitting process, reconfirm the film thicknesses and derive the absorption coefficient spectra of the films. The wavelength-dependent index (n) data ( calculated based on Cauchy's dispersion formula) for the amorphous garnet and garnet-oxide precursor thin layers deposited on glass (Corning Eagle XG, $0.5 \mathrm{~mm}$ thick) substrates, yields the following spectral dependency for BiDyIG sample, $n=2.1906+0.0459 / \lambda^{2}$, and for BiDyIG: $\mathrm{Bi}_{2} \mathrm{O}_{3}\left(17\right.$ vol. \%) composite sample, $\mathrm{n}=2.2105+0.0576 / \lambda^{2}$; for $\mathrm{BiDyIG}$ : $\mathrm{Bi}_{2} \mathrm{O}_{3}(23.3$ vol. \%) composite sample, index dispersion function $n=2.1961+0.0683 / \lambda^{2}$ was obtained.
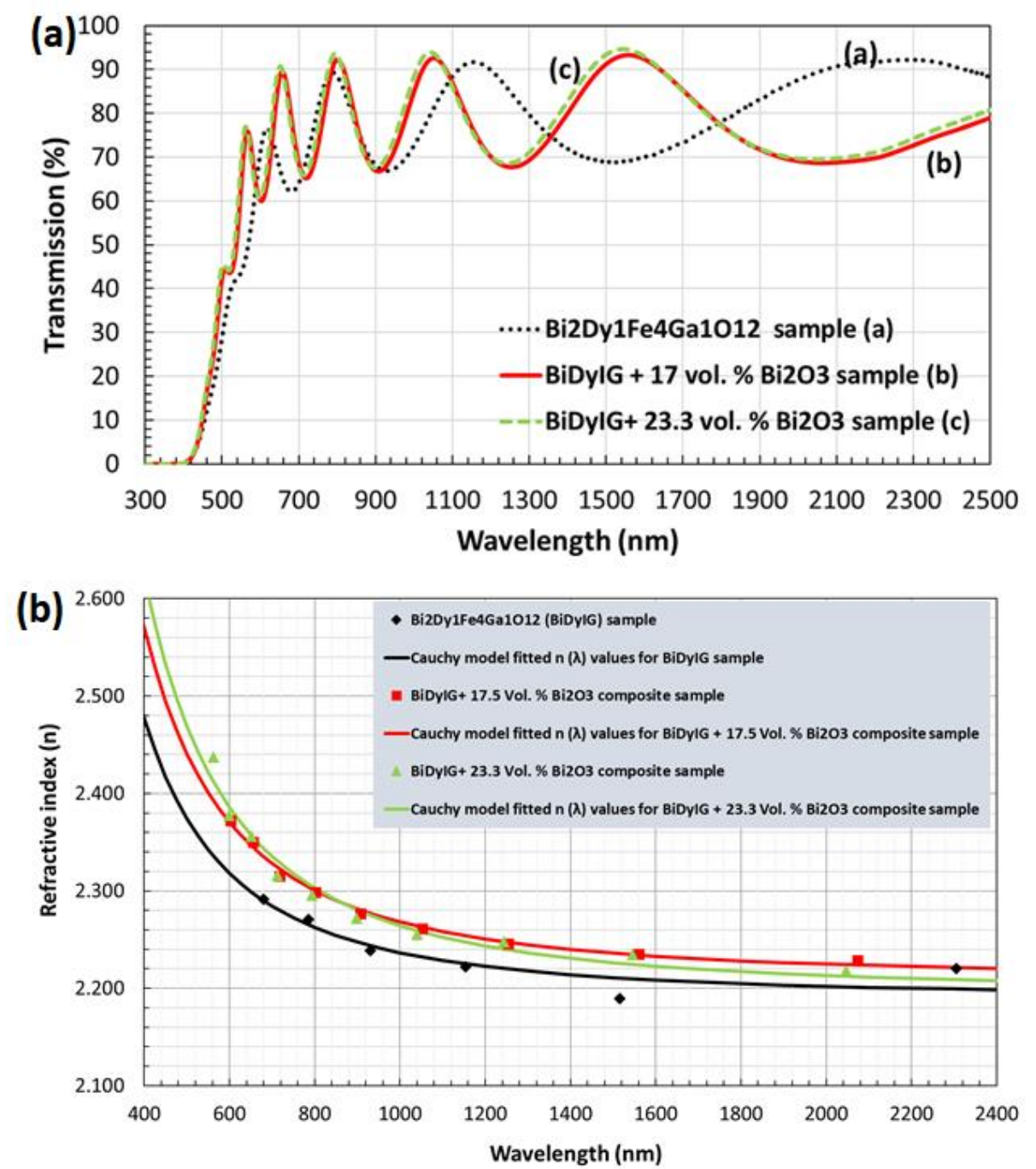

141 Figure 2. (a) Measured transmission spectra of as-deposited $\mathrm{Bi}_{2} \mathrm{Dy}_{1} \mathrm{Fe}_{4} \mathrm{Ga}_{1} \mathrm{O}_{12}$ (BiDyIG) and $\mathrm{BiDyIG} \mathrm{Bi}_{2} \mathrm{O}_{3}(17$ \& 23.3 vol. \%) composite thin films, (b) derived refractive index dispersion spectra for $\mathrm{Bi}_{2} \mathrm{Dy}_{1} \mathrm{Fe}_{4} \mathrm{Ga}_{1} \mathrm{O}_{12}$ (BiDyIG) and BiDyIG: $\mathrm{Bi}_{2} \mathrm{O}_{3}(17 \& 23.3$ vol. \%) composite thin films where the solid curves were determined according to Cauchy dispersion relationship. 
The calculated refractive indices at different wavelengths derived from Cauchy's relation as well as the calculated refractive index data points using the SEWM method were plotted and compared (as shown in Fig. 2b). It can be noted that the refractive index (n) is in the range of 2.2-2.6 in the visible region and decreases with increasing wavelength. In the long-wavelength region (above $1600 \mathrm{~nm}$ ), the refractive index seems to be asymptotically approaching a constant value. The volumetric fraction of excess $\mathrm{Bi}_{2} \mathrm{O}_{3}$ introduced into the $\mathrm{BiDyIG}$ system helps increase the refractive index of the composite films, however, this also shifts the absorption edge towards the shorter wavelength region (as seen in Fig.2a). Note that there are always significant differences that exist between the optical constants of the crystallized garnets and oxide-mix-based amorphous precursor layers. Therefore, it is also important to check the conformity of layer(s) to their designed spectral transmission specifications before annealing, especially when developing functional multilayer structures ${ }_{\llcorner}$such as MPC.

In our previous work, we have observed the effects of excess $\mathrm{Bi}_{2} \mathrm{O}_{3}$ addition to core materials within each garnet-related oxide mix (a generic composition type can be defined using a formula description such as $\left.(\mathrm{Bi}, \mathrm{Y}, \mathrm{Dy}, \mathrm{Lu}, \ldots)_{3}(\mathrm{Fe}, \mathrm{Al}, \mathrm{Ga}, \ldots)_{5} \mathrm{O}_{12}\right)$ on their annealing crystallization behaviour, and the final optical/MO properties. It was reported that an optimized amount of extra $\mathrm{Bi}_{2} \mathrm{O}_{3}$ content addition, can significantly improve the specific Faraday rotation, optical transparency and optical absorption coefficient across the visible spectral range, thus leading to achieving record-high MO quality factors in suitably annealed garnet-oxide composite thin films [66, 68]. Figure 3 shows the typical magnetic hysteresis loop properties of annealed garnet and GOC films measured through specific Faraday rotation at $532 \mathrm{~nm}$ using a Thorlabs PAX polarimeter system in conjunction with a custom-made calibrated electromagnet. Noteably, the annealed BiDyIG sample showed a nearly square-shaped hysteresis loops of Faraday rotation (Fig. 3a), whilst the annealed GOC films often showed practically perfectly "square" shapes of hysteresis loop (Fig. 3b) with perpendicular magnetic anisotropy, high (close to $100 \%$ ) remnant magnetization, and very sensitive magnetic switching behaviour.

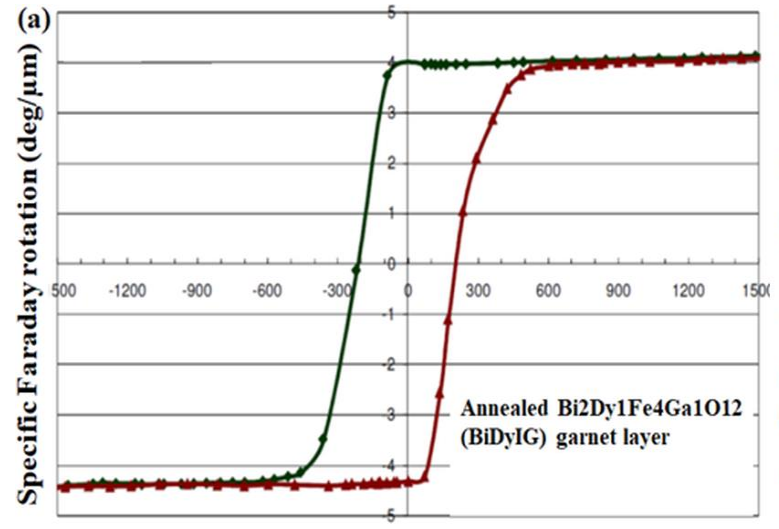

Magnetic field (Oe)

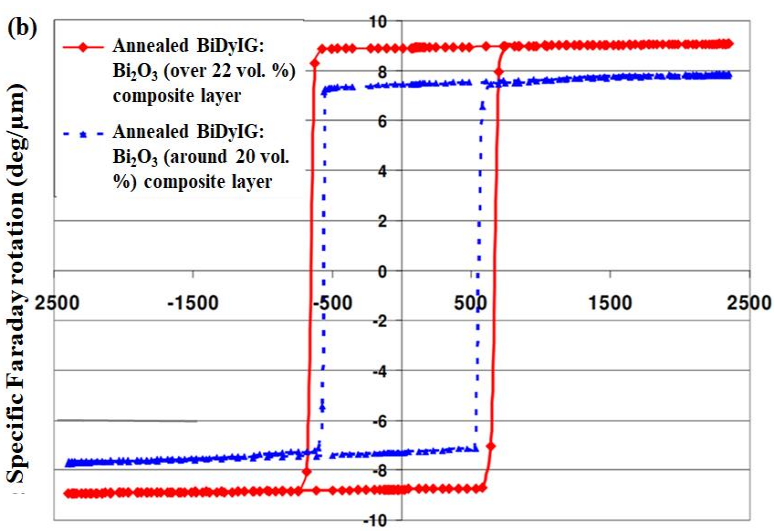

Magnetic field (Oe)

Figure 3. Hysteresis loops of specific Faraday rotation at $532 \mathrm{~nm}$ measured in sputtered garnet films. (a) Annealed (nanocrystalline) $\mathrm{Bi}_{2} \mathrm{Dy}_{1} \mathrm{Fe}_{4} \mathrm{Ga}_{1} \mathrm{O}_{12}$ (BiDyIG) sample, and (b) annealed $\mathrm{BiDyIG}: \mathrm{Bi}_{2} \mathrm{O}_{3}$ composite-type oxide-diluted thin films [66].

The strong uniaxial magnetic anisotropy in $\mathrm{BiDyIG}$ : $\mathrm{Bi}_{2} \mathrm{O}_{3}$ nano-composite films together with some degree of control over the coercive force and switching field properties (as shown in Fig. 3b) and excellent optical and magnetic properties, make them very attractive and promising for a large range of optoelectronic, photonics-related, sensing, and MO imaging applications.

We observed somewhat unconventional and remarkable magnetic switching properties for the first time in RF magnetron sputtered all-garnet multilayer thin-film structures, in which magnetosoft layers were sandwiched in-between two magneto-hard garnet material layers of identical composition type [76]. Both garnet material types possessed very large specific Faraday rotation 
182

183

184

185

186

187

188

189

190

191

192

193

194

195

196

197

198

199

200

201

202

203

across the visible spectral range $(\approx 6 \%$ m at $532 \mathrm{~nm}$ and $\sim 1.6 \% / \mu \mathrm{m}$ at $635 \mathrm{~nm}[66,68])$ and high magneto-optic $(\mathrm{MO})$ quality. The magnetic switching behavior of trilayers (illustrated in Fig. 4a), were characterized by way of measuring their Faraday rotation hysteresis loops. The samples were prepared on glass (Corning Eagle XG) and also GGG (111) substrates; the sputtering deposition was followed by post-deposition annealing crystallization (heat treatment process, $1 \mathrm{~h}$ at $570{ }^{\circ} \mathrm{C}$ ) conducted in air atmosphere. The amount of extra bismuth oxide content co-sputtered from a separate target $(17 \mathrm{vol} . \%)$ was selected to facilitate a notable increase in the specific Faraday rotation whilst at the same time avoiding a significant reduction in the upper limits of the annealing temperature range. X-ray diffraction (XRD) measurements (performed in the range of $2 \theta$ angles between $20^{\circ}$ and $70^{\circ}$, as shown in Fig. $4 \mathrm{~b}$ ) revealed the body-centered cubic lattice structure of different constituent garnet materials present inside annealed trilayers. Their microstructure type has been identified as being nanocrystalline on both substrate types. A notable and unexpected feature of hysteresis loop behavior (Fig. 4c) was the presence of an "intermediate saturation" state exhibiting the maximum Faraday rotation, which then was followed by conventional magnetization saturation state with reduced Faraday rotation, at increasing external magnetic fields above about $1 \mathrm{kOe}$. The final saturated Faraday rotation was observed at near $1.6 \mathrm{kOe}$, at below $50 \%$ of the maximum Faraday rotation angle seen at smaller fields. To the best of our knowledge, no prior (or later) reports of similar magnetic switching behaviours observed in any thin-film materials, relative to Ref. 76, can be found in the published literature. These exchange-coupled all-garnet multilayer structures demonstrated an attractive combination of optical and magnetic properties, and are of interest for emerging applications in optical sensors and isolators, ultrafast nanophotonics, magneto-plasmonics and possibly spintronics.
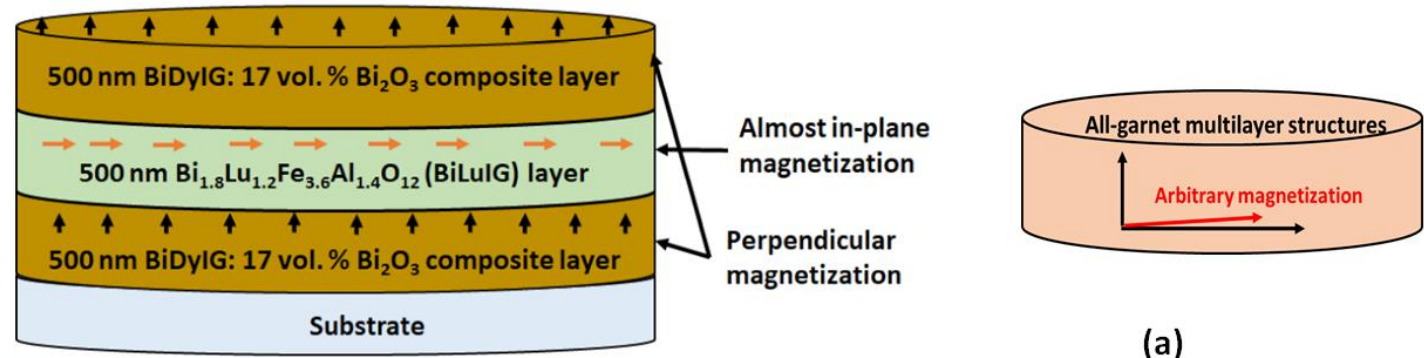

(a)
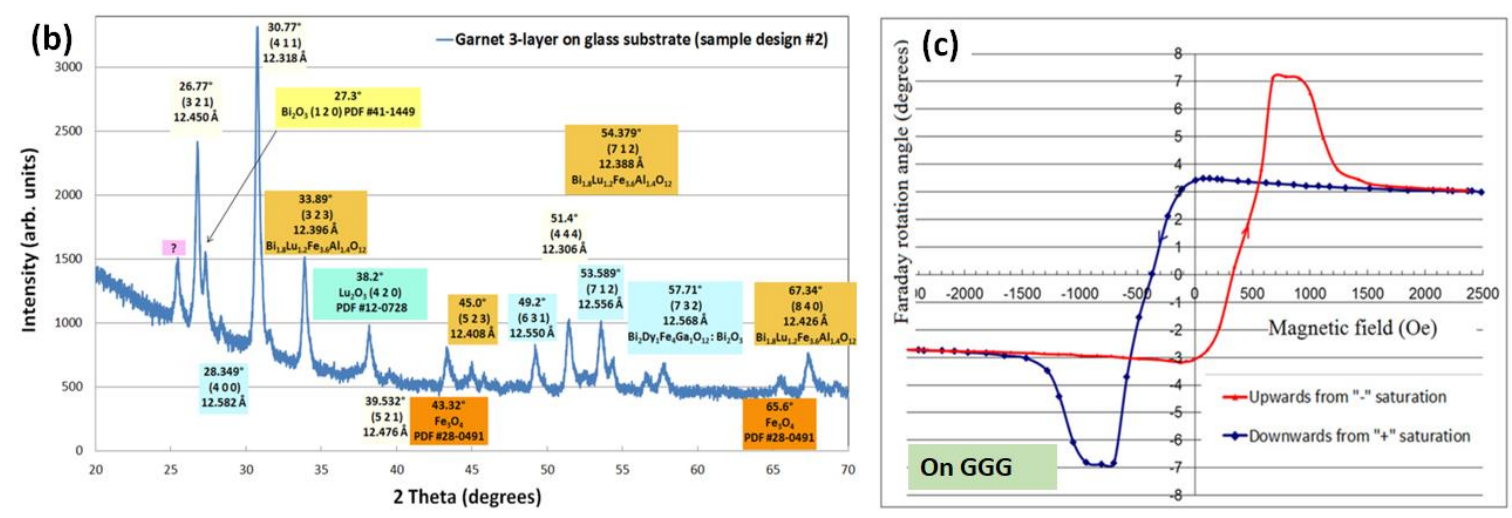

Figure 4. The schematic diagram of all-garnet multilayer structures together with the predicted layer-specific magnetization vector directions (a); XRD analysis results obtained from a multilayer garnet structure prepared on a glass substrate (b); the unconventional magnetic hysteresis loop of Faraday rotation $\left(^{\circ}\right)$ measured using green laser light source.

The objective of making this all-garnet trilayer structure was to investigate the potential of obtaining and controlling these special magnetic switching properties observed in the described trilayer types that are not attainable normally in any single-layer magnetic thin films. We note that the unconventional magnetic behavior has only been observed in trilayers employing co-sputtered 
nanocomposite-type outer magneto-hard layers. Further studies are on-going, aimed at achieving better control over the magnetic properties (e.g. coercive force, switching field(s), and saturation magnetization) in garnet multilayer structures having different combinations of high-performance garnet materials of various optimized thicknesses as well as stoichiometry types. Other active areas of ongoing research within our group include the investigations of the effects of the post-deposition oxygen plasma treatment of amorphous-phase garnet-precursors on the final magnetic and MO properties observed in crystallized films. Initial findings indicate that there exist optimized oxygen plasma post-treatment regimes, which lead to observing strong improvements in the MO quality of annealed thin garnet layers.

\section{Ruthenium-oxide thin-films grown on flexible and rigid substrates for cost-effective sensor electrodes}

Sputter-deposition process parameters such as total or partial gas pressure(s), process gas chemistry, substrate type, substrate-stage heating temperature, substrate-stage rotation rate, substrate-to-target distance, target rotation rate, and RF powder densities, are well-known to affect the growth and properties of thin-film materials. There are many reports published in the literature describing the necessity of sputter-deposition process parameter optimization for many applicationspecific oxide-based and other thin-film materials [78-88]. For example, sputter-deposition process parameters were studied and optimized to deposit ruthenium oxide $\left(\mathrm{RuO}_{2}\right)$ thin films with strong adhesion properties for manufacturing durable sensing electrodes [84, 88]. For the manufacture of sensors, it is important to control the material properties in order to obtain the desired functionality [89]. In this section, we present optimized R.F. sputter-deposition process parameters for the manufacture of highly-durable $\mathrm{RuO}_{2}$ thin-film electrodes on flexible and rigid substrates, along with the $\mathrm{pH}$ and temperature sensing performance of these electrodes.

Ruthenium oxide thin films feature very attractive properties for use in various sensing devices, such as $\mathrm{pH}$ sensing, cryogenic temperature sensing, and even bio-sensing applications [90-92]. In order to manufacture durable and therefore cost-effective electrodes, it is important to have strong adhesion of $\mathrm{RuO}_{2}$ to its substrate material. This requires optimization of multiple sputter-deposition process parameters, to overcome sputter-chamber pressure-dependent adhesion properties of $\mathrm{RuO}_{2}$ layers fabricated on different substrates [90].

\subsection{Experimental}

$\mathrm{RuO}_{2}$ thin-film electrodes (potentiometric, interdigitated and resistive) were deposited directly onto two different substrate materials (alumina and polyimide), as shown in Figure 5. In summary, $100 \mathrm{~nm}$ thick layers of $\mathrm{RuO}_{2}$ were deposited using $\mathrm{RF}$ magnetron sputtering from a metal-oxide $\left(\mathrm{RuO}_{2}\right)$ target $(99.95 \%$ purity) with $110 \mathrm{~W}$ sputter power, at room temperature, with 4 mTorr chamber pressure and 5:5 sccm Ar: $\mathrm{O}_{2}$ gas flow rate. Electrode patterns were achieved using a standard photolithographic process. 

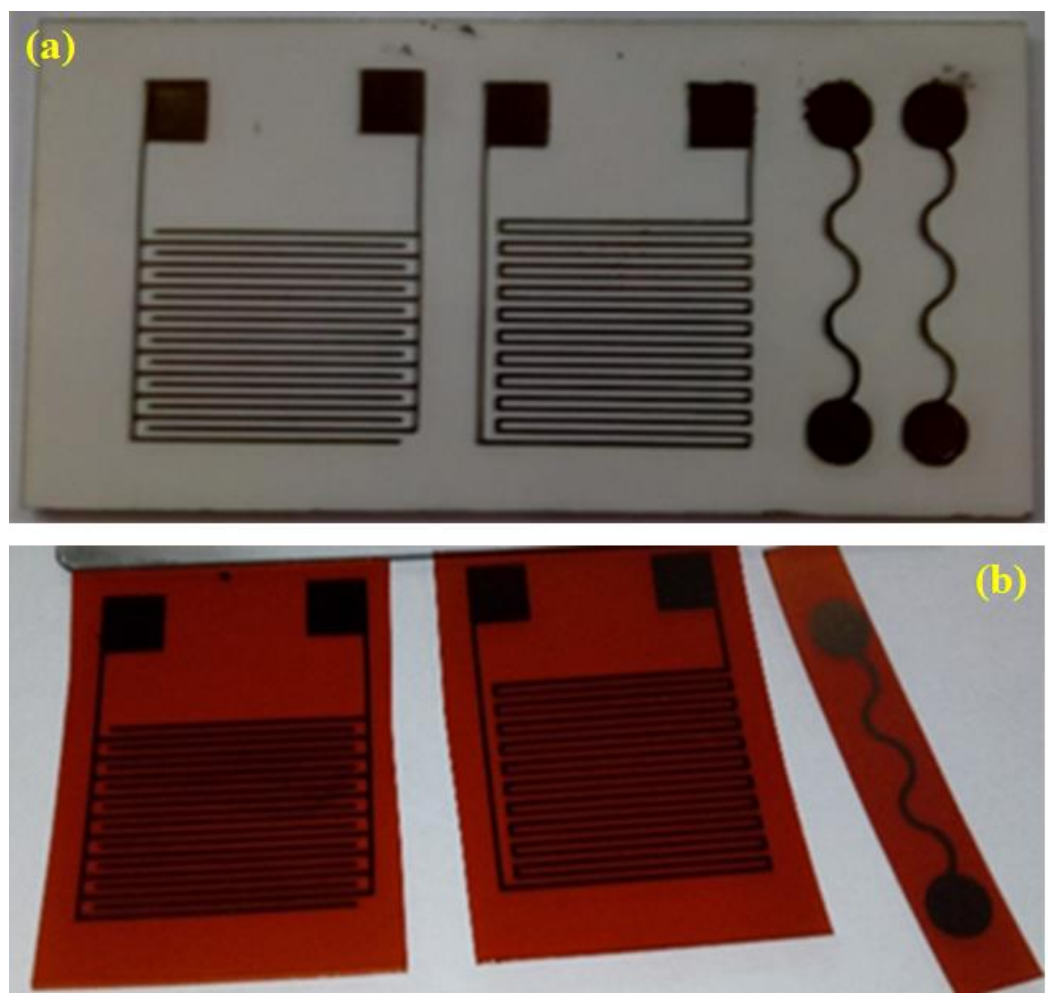

Figure 5. 100nm thick potentiometric, interdigitated and resistive $\mathrm{RuO}_{2}$ electrodes sputter deposited on alumina (a) and polyimide (b) substrates.

Potentiometric measurements were made using an Atlas Scientific ORP EZO circuit connected to PC via an Electrically Isolated USB EZO Carrier Board, with a commercially available glass $\mathrm{Ag}|\mathrm{AgCl}| 3 \mathrm{M} \mathrm{KCl}$ reference electrode (Sigma). Resistive electrodes were characterized with an Agilent 34410A high performance digital multimeter, using a 2-wire set-up to measure resistance. Measurements were made using commercially available buffer solutions (Rowe Scientific), for $\mathrm{pH}$. Whilst, temperature was controlled using a thermoelectric device and insulation.

\subsection{Results and comparison}

$\mathrm{RuO}_{2}$ films sputter deposited directly onto flexible polyimide substrates can be a cost-effective choice for use as a potentiometric electrode. It has been found experimentally that the polyimidebased electrodes prepared using a 4 mTorr chamber pressure and 1:1 $\mathrm{Ar}: \mathrm{O}_{2}$ gas ratio, showed excellent performance when used as potentiometric $\mathrm{pH}$ electrode (vs. $\mathrm{Ag}|\mathrm{AgCl}| \mathrm{KCl}$ reference electrode), exhibiting a reversible $( \pm 3.9 \mathrm{mV})$, linear $\left(\mathrm{R}^{2}=0.9994\right)$ and Nernstian $(57.5 \mathrm{mV} / \mathrm{pH}) \mathrm{pH}$ response, as shown in Fig. 6. The obtained result is comparable to previously reported $\mathrm{RuO}_{2} \mathrm{pH}$ electrodes prepared on alumina substrates, which also exhibited a reversible $( \pm 1.8 \mathrm{mV})$, linear $\left(\mathrm{R}^{2}=0.9999\right)$ and Nernstian $(59.1 \mathrm{mV} / \mathrm{pH}) \mathrm{pH}$ response [90]. The polyimide resistive and interdigitated electrodes failed when used as conductivity and temperature sensors, due to gradual delamination. However, the alumina-based resistive temperature sensor exhibited reversible $\left( \pm 0.01{ }^{\circ} \mathrm{C}\right)$ linear $\left(R^{2}=0.9999\right)$ response, which is comparable to some commercially available sensors as shown in Fig. 7 . 
(a)

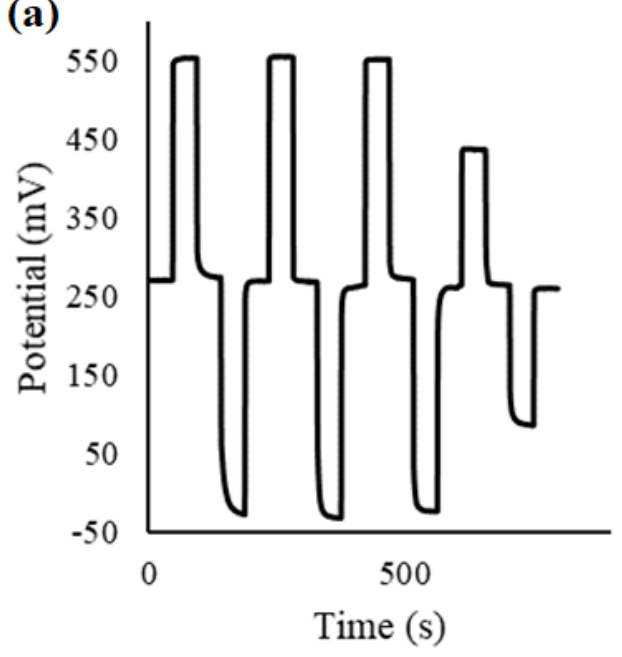

(b)

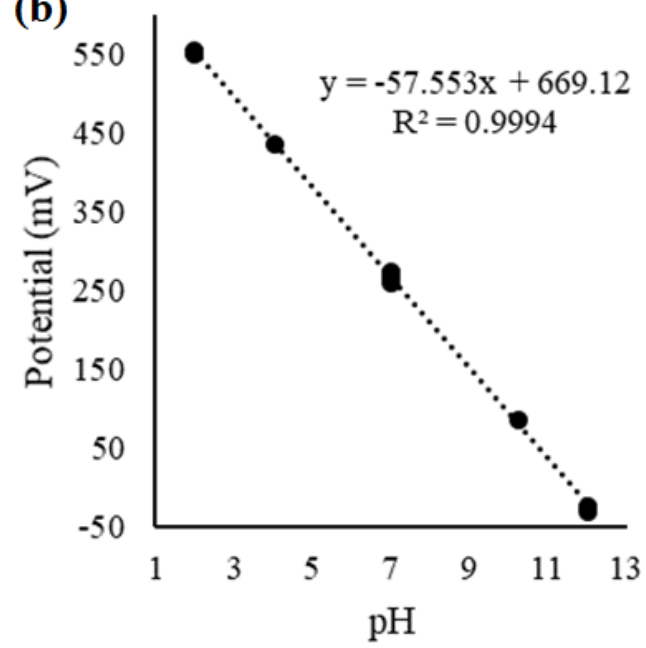

Figure 6. Electric potential recorded vs. a $\mathrm{Ag}|\mathrm{AgCl}| \mathrm{KCl}$ reference electrode for the potentiometric $\mathrm{RuO}_{2}$ electrode on polyimide substrate, in $\mathrm{pH} \mathrm{2,} \mathrm{4} \mathrm{7,} 10$ and 12 buffers (a), and the reversible linear Nernstian $\mathrm{pH}$ response of the electrode $(b)$.
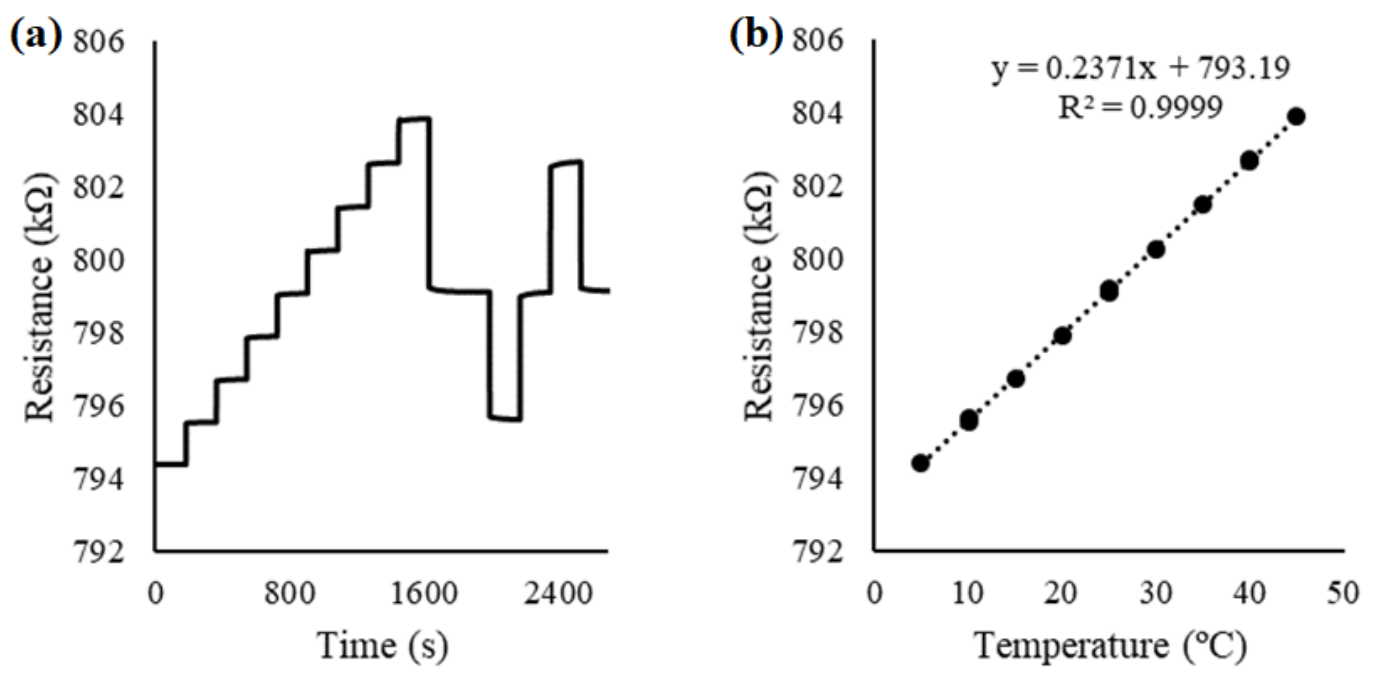

Figure 7. Electric resistance variations recorded for a $\mathrm{RuO}_{2}$ electrode on alumina substrate, at 5 to $45^{\circ} \mathrm{C}$ (a), and the reversible linear temperature response of the electrode $(b)$.

To summarize, durable metallic $\mathrm{RuO}_{2}$ thin films could only be deposited with a chamber pressure $\geq 4$ mTorr with argon: oxygen content in the chamber. $\mathrm{RuO}_{2}$ films deposited at pressures lower than 4 mTorr produced powdery films that rapidly delaminate from all substrates. The improved durability of these $\mathrm{RuO}_{2}$ electrodes allows for the development of reliable sensors, potentially for miniaturised applications or where conventional glass probes are not suitable, such as biomedical applications.

Other RF sputtered metal oxide materials investigated by our group included rare-earth oxide compositions such as $\mathrm{Er}_{2} \mathrm{O}_{3}, \mathrm{Dy}_{2} \mathrm{O}_{3}, \mathrm{Gd}_{2} \mathrm{O}_{3}$, and other, e.g. $\mathrm{Zr}_{2} \mathrm{O}_{3}, \mathrm{TiO}_{2}, \mathrm{SnO}_{2}$, and $\mathrm{Al}_{2} \mathrm{O}_{3}$. Intended applications included the scratch-proof and hydrophobic film layers, sensing applications, diffusion protection layers, and generic multilayer constituents. Two principal categories of deposition processes were explored with oxide materials: sputtering in pure-argon plasma and the processes run using argon-oxygen plasma mixes. Substantial differences in the resulting oxide material properties were observed, dependent on the deposition process type used. The main reason for the 
observed property differences was the oxygen loss occurring during sputtering deposition, which has often been possible to recover using high-temperature oven annealing processes.

\section{Metal-dielectric nanocomposite-based multilayer building blocks for transparent solar and thermal regulation coatings}

The development of modern energy-efficient glass and window products requires specialized thin-film coatings containing silver $(\mathrm{Ag})$ layer(s) to filter or reflect the infrared and far-infrared (thermal) radiation components of the solar spectrum, thus reducing the energy consumption in buildings. Also, surface plasmon resonance-based optical sensors require noble metal-dielectric interfaces, and have numerous commercial applications in gas, biochemical and chemical sensing due to their high sensitivity to the refractive index changes in a dielectric medium placed on top of ultra-thin metallic (Ag) films [93-96]. The deposition of the ultra-thin Ag layers with low surface roughness and high uniformity is the key to achieving the required application-specific optical properties. However, the deposition of ultra-thin (less than $20 \mathrm{~nm}$ ) Ag layers often results in forming morphologically uneven nano-islands, even when using the fine-tuned deposition processes ${ }_{L}$ such as RF magnetron sputtering $[97,98]$. The formation of these Ag nano-islands significantly affects the optical performance of multilayer metal-dielectric thin-film structures. Typically, reduced reflectivity across the near-infrared range results from the imperfect metal layer morphologies. Also, dielectric material layer deposited on top of these island-shaped ultra-thin Ag layers tend to "sink" into the spaces between these silver nano-islands, leading to strong optical property deviations from the designed response. Another issue associated with $\mathrm{Ag}$ is that it oxidizes very quickly, therefore the Ag layer has to be protected from oxidation even during the deposition of the next material layer in the thin-film multilayer sequence. Researchers have proposed and trialled the preparation of nanocomposites to overcome these issues related to the difficulties of forming ultra-thin Ag layers. Most of the relevant success stories were about depositing metal-dielectric nano-particle based composites [99-103].

We have prepared co-sputtered metal-dielectric nanocomposites (MDC) by developing a cosputtering process for $\mathrm{Ag}-\mathrm{MgF}_{2}$ system, with various volumetric contents of the dielectric phase added to the metal. We have also developed MDC-containing multilayer structures, and their characterisation results suggest that MDC layers can replace the pure-metal layers in multilayer optical coatings, thus offering a new possibility to design and fabricate highly durable and environmentally-stable coatings on glass suitable for solar and thermal regulation technologies [104]. In this section, we present the growth process details for thin-film single-layer MDC and newly developed MDC-containing multilayer coatings. Their measured optical characteristics are also reported. The transmission spectrum features of these newly-developed MDC-based multilayer building blocks appear to be promising for manufacturing cost-effective solar and thermal heat regulation coatings for the construction industry, in the near future.

\subsection{Deposition of MDC layers and multilayer structures}

Several batches of MDC $\left(\mathrm{Ag}+\mathrm{MgF}_{2}\right)$ films were deposited onto glass substrates by using the cosputtering process in an RF magnetron sputtering system. The volumetric fraction of dielectric $\left(\mathrm{MgF}_{2}\right)$ phase was controlled by adjusting the RF power densities applied to the $\mathrm{MgF}_{2}$ sputtering target during the co-sputtering process, after carefully calibrating the partial deposition rates for both $\mathrm{MgF}_{2}$ and Ag. The thicknesses of ultrathin composite films trialled were in the range between $12-25 \mathrm{~nm}$. After the successful growth of MDC layers, we prepared several multilayer structures introducing the optimized MDC layers along with surrounding oxide layers. Table 1 summarizes the deposition process parameters used to fabricate these metal-dielectric nanocomposite layers and MDC containing multilayer building blocks. The transmission and reflection spectra of MDC layers were measured just after the deposition using an Agilent Cary 5000 UV-VIS-NIR spectrophotometer. The reflection spectrum measurements were carried out using a custom-built reflection-mode optical 
354

355

356

357

358

359

360

361

measurement module mounted inside the spectrophotometer, which contained four mirrors adjusted at 45-degree tilts to form a periscope-type device as shown in Fig. 8.

Table 1. Sputtering process parameters used to deposit MDC single layer and MDC containing multilayer building blocks.

\begin{tabular}{|l|l|l|}
\hline \multicolumn{1}{|c|}{ Process parameters } & \multicolumn{1}{|c|}{$\begin{array}{c}\text { Layer structure } \\
\text { (single layer MDC) }\end{array}$} & \multicolumn{1}{|c|}{$\begin{array}{c}\text { Layer structure } \\
\text { (multilayers } \\
\text { containing MDC layer) }\end{array}$} \\
\hline Sputtering targets & $\mathrm{Ag}, \mathrm{MgF}_{2}$ & $\mathrm{Al}_{2} \mathrm{O}_{3}, \mathrm{Zr}_{2} \mathrm{O}_{3}, \mathrm{Ag}, \mathrm{MgF}_{2}$ \\
\hline RF Power & $\mathrm{Ag}(55-65 \mathrm{~W}), \mathrm{MgF}_{2}(83-95$ & $\begin{array}{l}\mathrm{Al}_{2} \mathrm{O}_{3}(190-195 \mathrm{~W}), \mathrm{Ag}(55 \\
-65 \mathrm{~W}), \mathrm{MgF}_{2}(83-95 \mathrm{~W})\end{array}$ \\
\hline Base pressure (Torr) & $5 \times 10^{-6}$ & $5 \times 10^{-6}$ \\
\hline Process gas & $\mathrm{Ar}$ & $\mathrm{Ar}$ \\
\hline Process pressure & $2-3 \mathrm{mTorr}$ & $1-3 \mathrm{mTorr}$ \\
\hline Substrate temperature $\left({ }^{\circ} \mathrm{C}\right)$ & $\mathrm{Room}$ temperature & Room temperature \\
\hline Post deposition heat treatment & $\mathrm{No}$ & $\mathrm{Up}$ to $500^{\circ} \mathrm{C}$ for $1-10$ hours \\
\hline
\end{tabular}

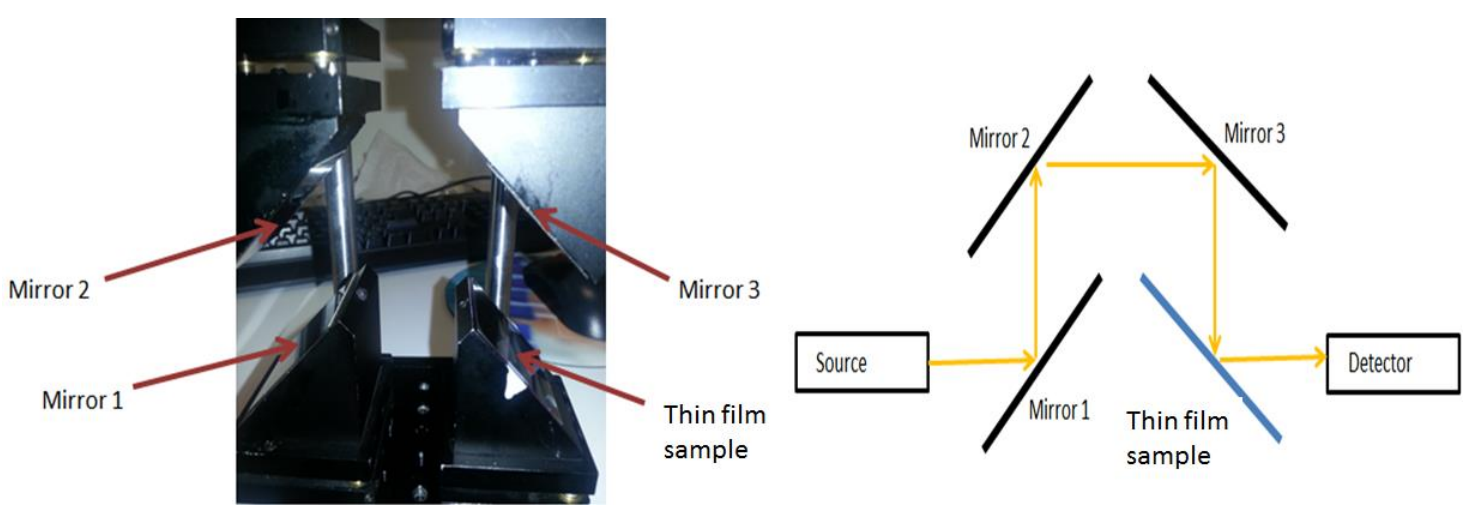

Figure 8. Schematic diagram of the optical system used in Cary 5000 spectrophotometer to measure the reflection spectrum of the thin film coatings on glass substrates.

Since our primary motivation for MDC materials development was to broaden the range of possible high-performance designs of heat-mirror-type coatings, and because the reflectivity of these coating types across the near-infrared range is their main performance indicator, developing both the transmission and reflection spectral measurements was necessary.

\subsection{Optical characteristics of MDC thin films and MDC-containing multilayer structures}

Figure 9 shows an example of the measured transmission and reflection spectrum of $\mathrm{Ag}+\mathrm{MgF}_{2}$ ( 5 vol. \%) composite $(\sim 20 \mathrm{~nm})$ thin-film. The transmission peak in this $\mathrm{Ag}+\mathrm{MgF}_{2}$ composite layer exhibited short-wavelength transmission and reflection features similar to the Ag layer of the same thickness. The optical absorption was calculated by subtracting the transmittance and reflectance of the composite layers using the formula $\mathrm{A}=1-\mathrm{T}-\mathrm{R}(\%)$, where $\mathrm{A}$ is the absorbed power fraction, $\mathrm{T}$ is the power transmission coefficient, and $\mathrm{R}$ is the power reflectivity. It was found that the $\mathrm{Ag}+5 \mathrm{vol} . \%$ $\mathrm{MgF}_{2}$ sample had a comparatively lower absorption (less than $9 \%$ by power) in the UV-Visible spectral range, which is close to that of the pure Ag layer. This indicates that the addition of $5 \mathrm{vol} . \%$ $\mathrm{MgF}_{2}$ into the Ag layer during the co-sputtering process can potentially improve the coating adhesion and stability aspects without compromising the plasmonics metal properties. 


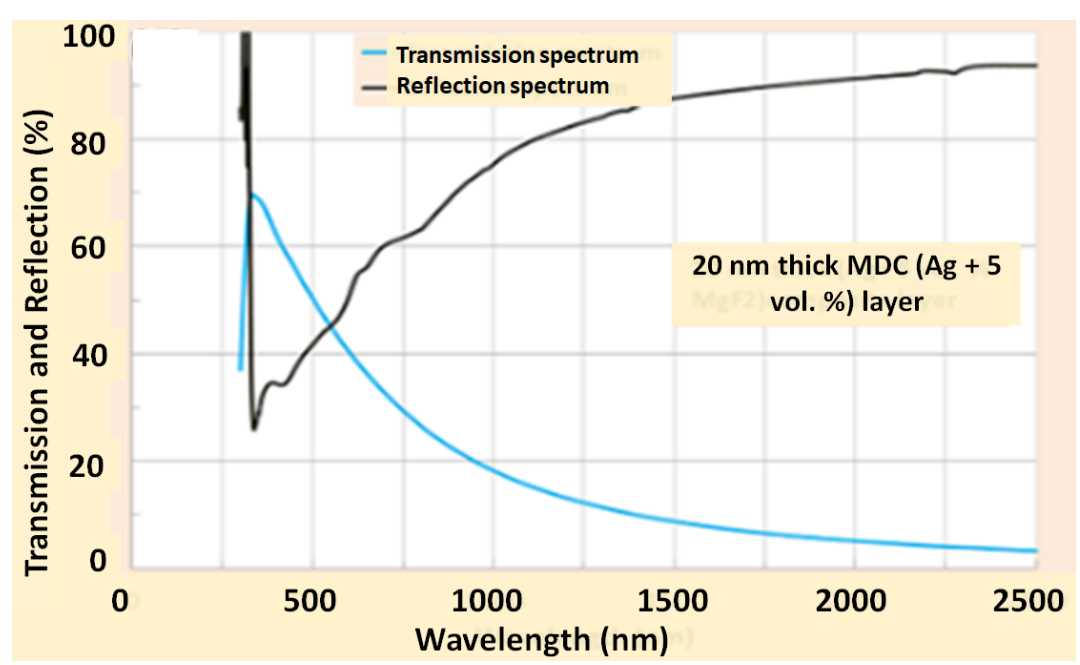

Figure 9. Measured transmission and reflection spectra of $\sim 20 \mathrm{~nm}$ thick Ag+ 5 vol. $\% \mathrm{MgF} 2$ composite layer, deposited onto glass substrate.

Several trilayer structures containing at least one MDC layer were deposited on clear glass substrates using one continuous sputtering run, and their optical performance was characterized. Figure 10 (a) shows the transmission spectrum of as-deposited multilayer coatings, where the layer structure consists of at least one MDC ( $\mathrm{Ag}+4-5 \mathrm{vol}$. \% $\left.\mathrm{MgF}_{2}\right)$ in comparison to that of a typical trilayer pure metal (Ag) based DMD-type coating. It can be noted that the use of a $25 \mathrm{~nm}$ MDC layer instead of a pure $15 \mathrm{~nm} \mathrm{Ag}$ layer resulted in better thermal radiation filtering performance without compromising the visible spectral transmission, whilst avoiding any potential layer morphologyrelated issues that usually affect ultrathin (thinner than about 17nm) layers. Experimental investigations revealed that the co-sputtered MDC (even comparatively thicker) layers with high metal volume content can be embedded into any type of multilayer structures for possibly improving the spectrally-selective transparency control, and structural properties of the coating whilst allowing significant design flexibility. Particularly important is the possibility of depositing MDC-type layers onto practically any underlying film layers, almost regardless of surface energy-related layer interface compatibilty considerations. The MDC based structures also demonstrated much lower thermal emissivity whilst maintaining the same superior visible transmission compared to the silverbased coatings, as shown in Fig. 10(a). 

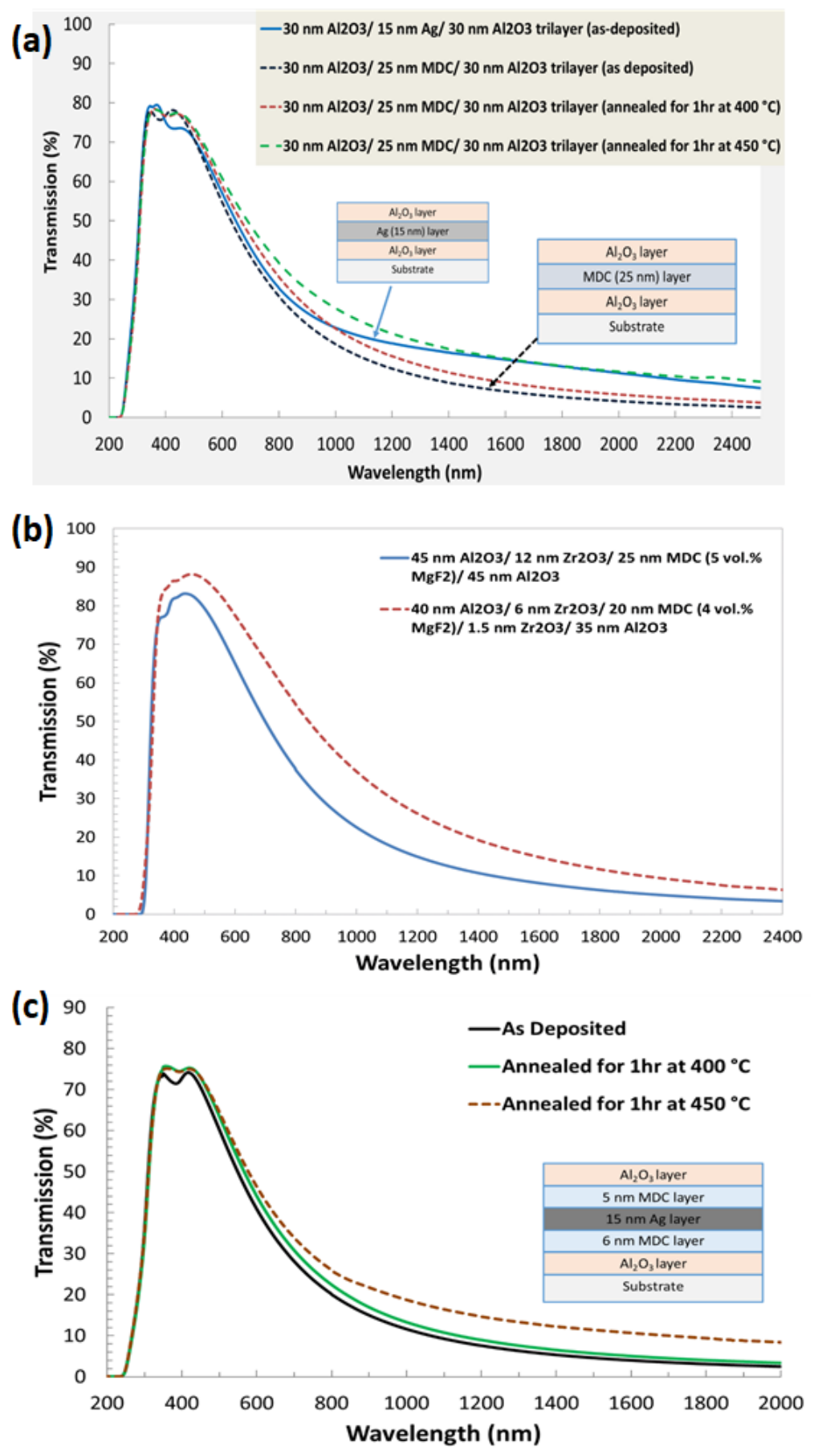

Figure 10. Measured transmission spectra of multilayer thin film structures containing a single (or double) metallic or MDC layer. (a) Transmission of a tri-layer MDC structure compared to that of a typical Ag layer within a DMD structure; thermal performance stability test results are also shown for the tri-layer MDC structure; (b) transmission spectra of multilayer structures containing MDC layer of different volumetric fractions of added dielectric, and (c) thermal performance stability test results for a complex DMD-type multilayer structure containing both the MDC outer-bracket sublayers and an ultra-thin pure-Ag core layer.

In order to investigate the design variations, material intercompatibility, durability and thermal stability properties of the MDC-based coatings, several different types of test multilayers (up to fivelayer structures) were developed, as shown in Fig. 10 (b, c). Figure 10 (b) shows the optical performance of an elementary (five layer-based) thin-film coating building blocks composed of a center MDC layer, surrounded by thin oxide-based "bracket layers" deposited by pure-argon sputtering process from a ceramic oxide target of $\mathrm{Zr}_{2} \mathrm{O}_{3}$. The addition of these ultrathin rare-earth 
oxide layers has led to broadenening the structure design possibilities in terms of improving the peak transmission and spectral selectivity. The optical performance variations observed in this particular five layer-based coatings confirmed the possibility of engineering a broader range of optical coatings for future solar and thermal regulation application in comparison with a simple dielectric-metaldielectric (DMD) trilayers or multilayers of similar spectral response. Figure 10(c) presents a more complex generalized MDC-type multilayer building block, which was subjected to extensive thermal stability (dry heat exposure) tests. The performance of the developed structure (before and after heat exposure in an air-filled lab oven) shows that the optical properties are comparable to some of the conventional multilayer structures containing pure Ag layers $[105,106]$. It can be seen clearly that the transmission spectra were found to be only slightly changed at temperatures near $400{ }^{\circ} \mathrm{C}$, which is a very encouraging result, and confirms that the very thin MDC barrier layers can play a vital role in protecting the ultra-thin core Ag layers within the multilayer structures. This confirms that the MDC layers can be used to enable arbitrarily complex high-stability low-E, heat-mirror, or filter-type optical coating designs of high spectral selectivity, on a range of optical substrates. Additionally, it is possible to engineer a broader range of reflected or transmitted colour properties, compared to pure metal-based designs, which are much more limited in terms of the optical materials selection.

\section{Conclusions}

We demonstrate a range of material system design possibilities for multiple practical applications provided by fine-tuning the RF magnetron sputtering technologies. We established numerous sputtering-based thin-film material synthesis processes at ECU, aiming at incorporating these optical materials into functional devices for sensing, optical spectra shaping, polarisation control, magnetic switching, and magnetic field visualization, among others. Three functionally different categories of thin-film material systems have been discussed, such as MO garnets, metal oxides, and metal-dielectric nanocomposites, and results have been presented describing their growth processes and relevant parameters, physical properties, and behavior. All of the characteristic results obtained from these material system types are of interest for use in practical field-specific applications in optics, magneto-optics, sensing, and renewable energy.

Author Contributions: All authors have made nearly equal contributions to the study and manuscript. M. N. A. planned and designed the manuscript. M. N. A., W. L., and M. V. discussed the contents and wrote the manuscript, K. A. revised the manuscript, and edited it further, contributing to the final group discussion outcome regarding the manuscript.

Funding: This research work is supported by Electron Science Research Institute, Edith Cowan University, WA, Australia. No external funding was received.

Acknowledgments: The authors would like to acknowledge Dr. Yamna El-Mouedden for making some characterization experiments with MDC-based thin films and for generating the results presented in Figure 9 also Fig. 8.

Conflicts of Interest: The authors declare no conflict of interest.

\section{References}

1. Grove, W. R. On the electro-chemical polarity of gases. Philos. Trans. R. Soc., 1852, Vol. 142, 87-101.

2. Wright, A. W. On the production of transparent metallic films by the electrical discharge in exhausted tubes. Am. J. Sci. Arts., 1877, Vol. 13, 49-55.

3. Greene J. E. Review Article: Tracing the recorded history of thin-film sputter deposition: From the 1800s to 2017. J. Vacuum Science \& Technology A, 2017, 35, 05C204-1-60.

4. Lakhtakia, A.; Messier, R. Nanoengineered Morphology and Optics, SPIE-The International Society for Optical Engineering, Bellingham, Washington, USA, 2005, Chapter-2, 27-48. 
5. Alfonso, E.; Olaya, J.; Cubillos, G. Thin film growth through sputtering technique and its applications. https://www.intechopen.com/books/crystallization-science-and-technology/thin-film-growththrough-sputtering-technique-and-its-applications.

6. Mattox, D. M. A short history: Magnetron sputtering deposition. https://www.svc.org/DigitalLibrary/documents/2015 Summer DMM.pdf.

7. Depla, D.; Mahieu, S.; Greene, J. E. Sputter deposition processes. https://core.ac.uk/download/pdf/55744819.pdf.

8. Anders, A.; Mattox, D. M. Magnetron Sputtering: An Unfinished Journey, Tutorial presentation, 58th Annual Technical Conference of the Society of Vacuum Coaters (April, 2015): available on, www.svc.org.

9. Mattox. D. M. The Foundations of Vacuum Coating Technology. William Andrew, The Boulevard, Langford Lane, Kidlington, Oxford, OX5 1GB, United Kingdom, and 50 Hampshire Street, 5th Floor, Cambridge, MA 02139, United States, 2018, Elsevier Inc.

10. Sarkar, J. Sputtering Materials for VLSI and Thin Film Devices. William Andrew, 2010, ISBN, 978-08155-1593-7

11. Lu, D. X.; Wong, E. M. W.; Pun, E. Y. B.; Chung, P. S.; Jia, G. C. PZT thin films by radio frequency magnetron sputtering. In: Lampropoulos G.A., Lessard R.A. (eds) Applications of Photonic Technology 2. Springer, Boston, MA, https://doi.org/10.1007/978-1-4757-9250-8 9.

12. Lin, K. T.; Wu, J. M. RF-magnetron sputtering of Titanium dioxide for microelectronics applications. J. J. Appl. Phys., 2004, Vol. 43 (1-1), 232-236.

13. Sakthivel, P.; Murugan, R.; Asaithambi, S.; Murugesan, K.; Rajendran, R. Ravi, G. Radio frequency magnetron sputtered $\mathrm{CdO}$ thin films for optoelectronic applications. J. Phys. Chem. Solids, 2018, Vol. 126, 1-10.

14. Gould, R. D.; Hassan, A. K.; Mahmood, F. S. Electronic properties of zinc oxide thin films prepared by RF magnetron sputtering for varistor applications. Int. J. Electronics, 1994, Vol. 76 (5), 895-906, DOI: $10.1080 / 00207219408925994$.

15. Chen, C.; Cheng, Y.; Dai, Q.; Song, H. Radio frequency magnetron sputtering deposition of $\mathrm{TiO}_{2}$ thin films and their perovskite solar cell applications. Sci. Rep., 2015, 5, 17684.

14. Singh, J.; Khan, S. A.; Shah, J.; Kotnala, R. K.; Mohapatra, S. Nanostructured $\mathrm{TiO}_{2}$ thin films prepared by RF magnetron sputtering for photocatalytic applications. Appl. Surf. Sci., 2017, Vol. 422, 953-961.

15. Pisarkiewicz, T.; Maziarz, W.; Rydosz, A.; Jankowski, H.; Sokulski, J. Deposition of nanocrystalline $\mathrm{WO}_{3}$ thin film using magnetron sputtered multilayer structure in view of gas sensor applications. IMCS 2012 - The 14th International Meeting on Chemical Sensors, 20-23 May, 2012, Nuremberg, Germany, DOI 10.5162/IMCS2012/P2.0.14.

16. Lee, S.; Kim, J. Y.; Lee, T. W.; Kim, W. K.; Kim, B. S.; Park, J. H.; Bae, J. S.; Cho, Y. C.; Kim, J.; Oh, M. W.; Hwang, C. S.; Jeong, S. Y. Fabrication of high-quality single-crystal Cu thin films using radio-frequency sputtering. Sci. Rep., 2014, Vol. 4: 6230.

17. Maurya, D.; Sardarinejad, A.; Alameh. K. Recent development in R. F. magnetron sputtered thin films for $\mathrm{pH}$ sensing applications-An overview. Coatings, 2014, Vol. 4 (4), 756-771.

18. Surmenev, R.; Vladescu, A.; Surmeneva, M.; Ivanova, A.; Braic, M.; Grubova, I.; Cotrut, C. M. Radio frequency magnetron sputter deposition as a tool for surface modification of medical implants, modern technologies for creating the thin-film systems and coatings. 2017, IntechOpen, DOI: 10.5772/66396.

19. Saikumar, A. K.; Nehate, S. D.; Sundaram, K. Review-RF sputtered films of $\mathrm{Gd}_{2} \mathrm{O}_{3}$. ECS J. Solid State Science and Technology, 2019, Vol. 8 (7), Q3064-Q3078.

20. Prosolov, K. A.; Popova, K. S.; Belyavskaya, O. A.; Rau, J. V.; Gross, K. A.; Ubelis, A.; Sharkeev, Y. P. RF magnetron-sputtered coatings deposited from biphasic calcium phosphate targets for biomedical implant applications. Bioactive Mateials, 2017, Vol. 2 (3), 170-176.

21. D'Heurle, F. M. Aluminum films deposited by rf sputtering. Metallurgical and Materials Transactions B, 1970, Vol. 1 (3), 725-732.

22. Kay, E.; Parmigiani, F.; Parrish, W. Microstructure of sputtered metal films grown in high- and lowpressure discharges. J. Vac. Sci. \& Techn., 1988, A 6, 3074. https://doi.org/10.1116/1.575477.

23. Rydosz, A.; Brudnik, A.; Staszek, K. Metal oxide thin films prepared by magnetron sputtering technology for volatile organic compound detection in the microwave frequency range. Materials, 2019, 12,877 . 
24. Verger, F.; Nazabal, V.; Colas, F.; Němec, P.; Cardinaud, C.; Baudet, E.; Chahal, R.; Rinnert, E.; Boukerma, K.; Peron, I.; Deputier, S.; Guilloux-Viry, M.; Guin, J. P.; Lhermite, H.; Moreac, A.; Compère, C.; Bureau, B. RF sputtered amorphous chalcogenide thin films for surface enhanced infrared absorption spectroscopy. Opt. Mat. Exp., 2013, Vol. 3 (12), 2112-2131.

25. Lee, H.; Huang, Y. T.; Horn, M. W.; Feng, S. P. Engineered optical and electrical performance of rfsputtered undoped nickel oxide thin films for inverted perovskite solar cells. Sci. Rep., 2018, Vol. 8, 5590.

26. Lee, J.C.; Kang, K.H.; Kim, S.K.; Park, I.J.; Song, J.; Yoon, K.H. Direct deposition of textured ZnO:Al TCO films by rf sputtering method for thin film solar cells. In proc. Conference Record of the TwentyNinth IEEE Photovoltaic Specialists Conference, 2002, 19-24 May 2002. New Orleans, LA, USA. 10.1109/PVSC.2002.1190844.

27. Sanal, K. C.; Morales,R. B .; Castrejón, O. L.; Nairz, P. K.; Nair, M. T. S. Thin Film Zn-Mg-Al-O Produced by r. f. sputtering used in antimony sulfide solar cells. J. Electrochem. Soc., 2019, Vol. 166 (5), H3119-H3124, doi: 10.1149/2.0171905jes

28. S. Jaydeep, S. Yadav, B. P. Malla, A. R. Kulkarni, and N. Venkatramani, “Growth and dielectric behavior of radio frequency magnetron-sputtered lead magnesium niobate thin films" Appl. Phys. Lett. 81 (2002) 3840-3842.

29. Lee, N. Y.; Sekine, T.; Ito, Y.; Uchino, K. Deposition profile of RF-magnetron-sputtered $\mathrm{BaTiO}_{3}$ thin films J. J. Appl. Phys., 1994, Vol 33 (3), 1484-1488.

30. Hishmeh, G.A.; Barr, T.L.; Sklyarov, A.; Hardcastle, S. Thin polymer films prepared by radio frequency plasma sputtering of polytetrafluoroethylene and polyetherimide targets. J. Vac. Sci. Technol. A Vac. Surf. Films, 1996, 14, 1330-1338.

31. Kylián, O.; , Shelemin, A.; Solař, P.; Pleskunov, P.; Nikitin, D.; Kuzminova, A.; Štefaníková, R.; Kúš, P.; Cieslar, M.; Hanuš, J.; Choukourov, A.; Biederman, H. Magnetron Sputtering of Polymeric Targets: From Thin Films to Heterogeneous Metal/Plasma. Materials, 2019, 12, 2366.

32. Stelmashuk, V.; Biederman, H.; Slavínská, D.; Trchová, M.; Hlidek, P. Rf magnetron sputtering of polypropylene. Vacuum, 2004, 75, 207-215.

33. Hanus, J.; Kousal, J.; Choukourov, A.; Biederman, H.; Slavinska, D. RF magnetron sputtering of poly(propylene) in a mixture of argon and nitrogen. Plasma Process. Polym., 2007, 4, 806-811.

34. https://www.prnewswire.com/news-releases/sputtering-targets-and-sputtered-films-technology-andmarkets-300418821.html, accessed in February 2019.

35. https://www.marketwatch.com/press-release/thin-film-materials-market-is-expected-to-witness-asubstantial-growth-from-2018-to-2024-2018-10-12, accessed in March 2019.

36. Geller, S. Crystal chemistry of garnets. Z. Kristallographie, 1967, Bd. 125, S. 1-47

37. Novak, A.; Gibbs, G. V. The crystal chemistry of the silicate garnets. The American Mineralogist, 1971, Vol. 56.

38. Zvezdin, A. K.; Kotov, V. A. Modern Magnetooptics and Magnetooptical Materials. Institute of Physics Publishing, Bristol and Philadelphia, ISBN 075030362X, 1997.

39. Buhrer, C. F. Faraday rotation and dichroism of bismuth calcium vanadium iron garnet. J. Appl. Phys., 1969, 40, 4500.

40. Freiser, M. J. A survey of magnetooptic effects. IEEE. Trans.Mag., 1968, Vol. Mag-4 (2), 152-161.

41. Scott G. B.; Lacklison, D. E. Magnetooptic properties and applications of Bismuth substituted iron garnets. IEEE Trans. Magn., 1976, Vol. 12(4), 292-311.

42. Taketoshi, H.; Yukio, M.; Junichiro, N. Growth and characterization of Liquid-Phase Epitaxial BiSubstituted iron garnet films for magneto-optic application. J. J. Appl. Phys., 1985, Vol. 24 (10).

43. Huang, M.; Zhang, S. A new Bi-substituted rare-earth iron garnet for a wideband and temperaturestabilized optical isolator. J. Mater. Res., 2000, Vol. 15 (8), 1665-1668.

44. Anoikin E. V.; Sides, P. J. Plasma-activated chemical vapor deposition of Bismuth-substituted iron garnets for magneto-optical data storage. IEEE Trans. Magn., 1995, Vol. 31 (6), 3239-3241.

45. Syvorotka, I. M.; Ubizskii, S. B.; Kucera, M.; Kuhn M.; Vertesy, Z. Growth and characterization of Bi, Prand $\mathrm{Bi}$, Sc-substituted lutetium iron garnet films with planar magnetization for magneto-optic visualization. J. Phys. D: Appl. Phys., 2001, 34, 1178-1187.

46. kahl, S.; Grishin, A. M.; Kharstev, S. I.; Kawano K.;. Abell, J. S. Bi3Fe5O12 thin film visulaizer. IEEE Trans. Mag. 2001, Vol. 3 (1). 
47. Levy, M. The on-chip integration of magnetooptic waveguide isolators. IEEE, Quantum Elec., 2002, Vol. 8(6), 1300-1306.

48. Khartsev S. I.; Grishin, A. M. [Bi3 $\left.\mathrm{Fe}_{5} \mathrm{O}_{12} / \mathrm{Gd}_{3} \mathrm{Ga}_{5} \mathrm{O}_{12}\right]^{\mathrm{m}}$ magneto-optical photonic crystals. Appl. Phys. Lett., 2005, 87, 122504.

49. Kang, S.; Yin, S.; Adyam, V.; Li, Q.; Zhu, Y. $\mathrm{Bi}_{3} \mathrm{Fe}_{4} \mathrm{Ga}_{1} \mathrm{O}_{12}$ garnet properties and its application to ultrafast switching in the visible spectrum," IEEE Trans. Magn., 2007, Vol. 43 (9), 3656-3660.

50. Drezdzon, S. M.; Yoshie, T. On-chip waveguide isolator based on bismuth iron garnet operating via nonreciprocal single-mode cutoff. Opt. Express., 2009, Vol. 17 (11), 9276-9281.

51. Nur-E-Alam, M.; Vasiliev, M.; Alameh K.; Valli, C. Magneto-optical visualisation for high-resolution forensic data recovery using advanced thin film nano-materials. In Proc. International Cyber Resilience (SECAU 2010), 23-24 August 2010, pp-78-82, Perth, WA, Australia.

52. Bi, L.; Hu, J.; Jiang, P.; Kim, H. S.; Kim, D. H.; Onbasli, M. C.; Dionne, F. F.; Ross, C. A. Magneto-optical thin films for on-chip monolithic integration of non-reciprocal photonic devices. Materials., 2013, 6, 5094-5117.

53. Belotelov, V. I.; Kreilkamp, L. E.; Akimov, I. A.; Kalish, A. N.; Bykov, D. A.; Kasture, S.; Yallapragada, V. J.; Gopal, A. V.; Grishin, A. M.; Khartsev, S. I.; Nur-E-Alam, M.; Vasiliev, M.; Doskolovich, L. L.; Yakovlev, D. R.; Alameh, K.; Zvezdin, A.K.; Bayer, M. Plasmon mediated magneto-optical transparency. Nat. Coms., 2013, 4:2128, doi: 10.1038/ncomms3128.

54. Kuz'michev, A. N.; Kreilkamp, L. E.; Nur-E-Alam, M.; Bezus, E.; Vasiliev, M.; Akimov, I. A.; Alameh, K.; Bayer, M.; Belotelov, V. I. Tunable optical nanocavity of iron-garnet with a buried metal layer. Materials, 2015, 8(6), 3012-3023.

55. Du, Q.; Fakhrul, T.; Zhang, Y.; Hu, J.; Ross, C. A. Monolithic magneto-optical oxide thin films for onchip optical isolation. MRS Bulletin. 2018, 43, 413-418.

56. Krumme, J. P.; Doormann, V.; Willich, J. Bismuth iron garnet films prepared by rf magnetron sputtering. J. Appl. Phys., 1985, Vol. 57, 3885-3887.

57. Yamaga, M.; Yusa, K.; Miyazaki, Y. Optical waveguide of Nd-Doped garnet thin film RF-sputtered on $\mathrm{Y}_{3} \mathrm{Al}_{5} \mathrm{O}_{12}$ substrate. J. J. Appl. Phys., 1986, Vol. 25 (1-2) 194-199.

58. Ostoréro, J.; Escorne, M.; Pecheron-Guegan, A. Dy3 $\mathrm{Fe}_{5} \mathrm{O}_{12}$ garnet thin films grown from sputtering of metallic targets. J. Appl. Phys., 1994, 75, 6103, doi.org/10.1063/1.355474.

59. Park, M. B.; Cho, N. H. Structural and magnetic characteristics of yttrium iron garnet (YIG, Ce : YIG) films prepared by RF magnetron sputter techniques. J. Magn., Magn., Mat., 2001, Vol. 231 (2-3), 253-264.

60. Boudiar, T.; Payet-Gervy, B.; Blanc-Mignon, M. F.; Rousseau, J. J.; Berre, M. L.; Joisten, H. Magnetooptical properties of yttrium iron garnet (YIG) thin films elaborated by radio frequency sputtering. $J$. Mag. Mag. Mat., 2004, 284, 77-85.

61. Gomi, M.; Tanida, T.; Abe, M. RF sputtering of highly Bi-substituted garnet films on glass substrates for magneto-optic memory. J. Appl. Phys., 1985, Vol. 57 (1), 3888-3890.

62. Challeton, D.; Bechevet, B.; Rolland B.; Armand, M. F. RF sputtering of Bi-substituted garnet films for magneto-optic memory. J. Magn. Magn. Mat., 1990, 83, 37-38.

63. Deng, Y.; Fowlkes, J. D.; Rack, P. D.; Fitz-Gerald, J. M. Thin film rf magnetron sputtering of gadoliniumdoped yttrium aluminum garnet ultraviolet emitting materials. Opt. Mats., 2006, Vol 29(1-2), 183-191.

64. Lobe, S.; Dellen, C.; Finsterbusch, M.; Gehrke, H. G.; Sebold, D.; Tsai, C. L.; Uhlenbruck, S.; Guillon. O. Radio frequency magnetron sputtering of $\mathrm{Li}_{7} \mathrm{La}_{3} \mathrm{Zr}_{2} \mathrm{O}_{12}$ thin films for solid-state batteries. J. Power Sources, 2016, Vol. 307, 684-689.

65. Bhoi, B.; Venkataramani, N.; Aiyar, R. P. R. C.; Prasad, S.; Kostylev, M. Effect of annealing on the structural and FMR properties of epitaxial YIG thin films grown by RF magnetron sputtering. IEEE. Trans. Mag., 2018, Vol 54 (11), DOI: 10.1109/TMAG.2018.2842260.

66. Vasiliev, M.; Nur-E-Alam, M.; Kotov, V. A.; Alameh, K.; Belotelov, V. I.; Burkov, V. I.; Zvezdin A. K. RF magnetron sputtered (BiDy)3(FeGa)5O12:Bi2O3 composite materials possessing record magnetooptic quality in the visible spectral region. Opt. Express, 2009, Vol. 17 (22), 19519-19535.

67. Vasiliev, M.; Nur-E-Alam, M.; Perumal, P.; Kotov, V. A.; Alameh, K.; Lee Y. T.; Lee, Y. P. Annealing behavior and crystal structure of RF-sputtered bi-substituted dysprosium iron garnet films having excess co-sputtered bi-oxide content. J. Phys. D: Appl. Phys. 2011, 44. 
68. Nur-E-Alam, M.; Vasiliev, M.; Kotov, V. A.; Alameh, K. Highly bismuth-substituted, recordperformance magneto-optic garnet materials with low coercivity for applications in integrated optics, photonic crystals, imaging and sensing. Opt. Mat. Exp., 2011, Vol. 1 (3), 413-427.

69. Nur-E-Alam, M.; Vasiliev, M.; Alameh, K. Bi3 Fes $\mathrm{O}_{12}$ : $\mathrm{Dy}_{2} \mathrm{O}_{3}$ composite thin film materials for magnetophotonics and magneto-plasmonics. Opt. Mat. Exp., 2014, Vol. 4 (9), 1866-1875.

70. Nur-E-Alam, M.; Vasiliev, M.; Alameh, K.; Kotov, V. A.; Demidov, V.; Balabanov, D. YIG: $\mathrm{Bi}_{2} \mathrm{O}_{3}$ nanocomposite thin films for magneto-optic and microwave applications. J. Nanomat., 2015, Article ID 182691, doi.org/10.1155/2015/182691.

71. Nur-E-Alam, M.; Vasiliev, M.; Alameh, K. High-performance RF-sputtered Bi-substituted iron garnet thin films with almost in-plane magnetization. Opt. Mat. Exp., 2017, Vol. 7 (3), 676-686.

72. Kotov, V. A.; Shavrov, V. G.; Popkov, A. F.; Vasiliev, M.; Alameh, K.; Nur-E-Alam, M.; Alyabyeva, L. N.; Balabanov, D. E.; Burkov, V. I.; Virchenko, M. K. Magneto-optic properties of ultrathin nanocrystalline ferrite garnet films in the $8 \mathrm{~K}$ to $300 \mathrm{~K}$ temperature interval. J. Nanomat., 2018, Article ID 7605620, doi.org/10.1155/2018/7605620.

73. Nur-E-Alam, M.; Vasiliev, M.; Belotelov, V.; Alameh, K. Properties of ferrite garnet (Bi, Lu, Y)3(Fe, Ga)5O12 thin film materials prepared by RF magnetron sputtering. Nanomaterials, 2018, 8, 355; doi:10.3390/nano8050355.

74. Swanepoel, R. Determination of the thickness and optical constants of amorphous silicon. J. Phys. E Sci. Instrum. 1983, 16, 1214-1222.

75. Vasiliev, M.; Alameh K.; Nur-E-Alam, M. Analysis, optimization, and characterization of magnetic photonic crystal structures and thin-film material layers. Technologies, 2019, 7 (3), 49, doi.org/10.3390/technologies7030049.

76. Nur-E-Alam, M.; Vasiliev, M.; Kotov, V. A.; Balavanov, D. E.; Akimov, I. A.; Alameh, K. Properties of exchanged coupled all-garnet magneto-optic thin film multilayer structures. Materials, 2015, 8(4), 19761992.

77. Kotov, V. A.; Popkov, A. F.; Soloviev, S. V.; Vasiliev, M.; Alameh, K.; Nur-E-Alam, M.; Balabanov, D. E. Magnetic heterostructures with low coercivity for high-performance magneto-optic devices. J. Phys. D: Appl. Phys., 2013, 46, 035001, doi:10.1088/0022-3727/46/3/035001.

78. Rabeh, M.B.; Touatti, R.; Kanzari, M. Substrate temperature effects on structural optical and electrical properties of vacuum evaporated Cu2ZnSnS4 thin films. Int. J. Eng. Pract. Res., 2013, 2, 71-76.

79. Yang, Q.; Zhang, H.; Wen, Q.; Liu, Y.J. Effects of off-stoichiometry and density on the magnetic and magneto-optical properties of yttrium iron garnet films by magnetron sputtering method. Appl. Phys., 2010, 108, 073901.

80. M. C. Jiang and T. B. Wu, "The effect of electrode composition on rf magnetron sputtering deposition of $\mathrm{Pb}[(\mathrm{Mg} 1 / 3 \mathrm{Nb} 2 / 3) 0.7 \mathrm{Ti} 0.3] \mathrm{O} 3$ films", J. Mater. Res., 9 (1994) 1879- 1886.

81. Park, J. Y.; Heo, J. K.; Kang, Y. C. The properties of RF sputtered Zirconium oxide thin films at different plasma gas ratio. 2010Bulletin- Korean Chemical Society 31(2):397-400, DOI: 10.5012/bkcs.2010.31.02.397.

82. Hamada, K.; Ogawa, T.; Okumura, H.; Ishihara, K. N. The effect of substrate roughness on the properties of RF sputtered AZO thin film. MRS Commun., 2019, Vol. 9(2), 697-701.

83. Ghorannevis, Z.; Akbarnejad, E.; Ghoranneviss, M. Effects of various deposition times and RF powers on CdTe thin film growth using magnetron sputtering. Journal of Theoretical and Applied Physics, 2016, Vol. 10(3), 225-231.

84. Reddy, Y. K. V.; Mergel, D. Structural and electrical properties of RuO2 thin films prepared by rfmagnetron sputtering and annealing at different temperatures, J. Mater. Sci. Mater. Electron., 2006, 17, 1029-1034.

85. Tien, C. L.; Lin, H. Y.; Chang, C. K.; Tang, C. J. Effect of oxygen flow rate on the optical, electrical, and mechanical properties of dc sputtering ITO thin films. Advances in Condensed Matter Physics, 2018, Article ID 2647282, https://doi.org/10.1155/2018/2647282

86. Haque, F.; Rahman, K. S.; Islam, M. A.; Rashid, M. J.; Akhtaruzzaman, M.; Alam, M. M.; Alothman, Z. A.; Sopian, K.; Amin, N. Growth optimization of ZnS thin films by RF magnetron sputtering as prospective buffer layer in thin film solar cells. Chalcogenide Lett., 2014, Vol. 11(4), 189-197. 
87. Tehranchi, M.M.; Hamidi, S.M.; Hasanpour, A.; Mozaffari, M.; Amighian, J. The effect of target rotation rate on structural and morphological properties of thin garnet films fabricated by pulsed laser deposition. Opt. Laser Technol. 2011, 43, 609-612.

88. Lonsdale, W. Development, manufacture and application of a solid-state $\mathrm{pH}$ sensor using ruthenium oxide. PhD Theses., 2018, Retrieved from https://ro.ecu.edu.au/theses/2095

89. Stradiotto, N. R.; Yamanaka, H.; Zanoni, M. V. B. Review electrochemical sensors : A powerful tool in analytical chemistry. J. Braz. Chem. Soc., 2003, 14, 159-173.

90. Lonsdale, W.; Shylendra, S. P.; Brouwer, S.; Wajrak, M.; Alameh, K. Application of ruthenium oxide pH sensitive electrode to samples with high redox interference. Sensors Actuators, B Chem., 2018, 273, 12221225.

91. Bat'ko, I.; Flachbatt, K.; Design of $\mathrm{RuO}_{2}$-based thermometers the millikelvin temperature range. Cryogenics., 1995, 35, 105-108.

92. Brischwein, M.; Grothe, H.; Wiest, J.; Zottmann, M.; Ressler, J.; Wolf, B.; Planar Ruthenium Oxide sensors for Cell-on-a-Chip metabolic studies. Chem. Analityczna. 2009, 54, 1193-1201.

93. Mohelnikova, J. Materials for reflective coatings of window glass applications. Construction and Building Materials, 2009, Vol. 23, 1993-1998.

94. Al-Kuhaili, M. F.; Al-Aswad, A. H.; Durrani, S. M. A.; Bakhtiari, I. A. Energy-saving transparent heat mirrors based on tungsten oxide-gold $\mathrm{WO}_{3} / \mathrm{Au} / \mathrm{WO}_{3}$ multilayer structures," Solar Energy, 2012, Vol. 86, 3183-3189.

95. Kanu S. S.; Binions, R. Thin films for solar control applications. Proceedings of the Royal Society aMathematical Physical and Engineering Sciences, 2010, Vol. 466, 19-44.

96. Mouedden, Y. E.; Alghamedi, R.; Nur-E-Alam, M.; Vasiliev, M.; Alameh, K. Thin film coatings for solar and thermal radiation control prepared by physical vapour deposition," In Proc. Int. Conf. on Highcapacity Optical Networks and Enabling Technologies Conference 2012, HONET 2012, December 12 14, 2012, Istanbul, Turkey.

97. Chen, W.; Thoreson, M. D.; Kildishev, A. V.; Shalaev, V. M. Ultra-thin ultra-smooth and low loss silver and silver-silica composite films for superlensing applications. https://engineering.purdue.edu/ shalaev/Publication_list_files/QThE4.pdf

98. Anders, A.; Byon, E.; Kim, D.; Fukuda, K.; Lim, S. H.N. Smoothing of ultrathin silver films by transition metal seeding. Solid State Communications, 2006, Vol. 140 (5) 225-229.

99. Yu, B.; Leung, K. M.; Guo, Q.; Lau W. M.; Yang, J. Synthesis of Ag-TiO2 composite nano thin film for antimicrobial application. Nanotechnology, 2011, 22, 115603.

100. Cummings, K. D.; Garland, J. C.; Tanner, D. B. Optical properties of a small-particle composite. Phys. Rev. B, 1984, Vol. 30(8), 4170-4182.

101. Nielsen, R. B.; Thoreson, M. D.; Chen, W.; Kristensen, A.; Hvam, J. M.; Shalaev, V. M.; Boltasseva, A. Toward superlensing with metal-dielectric composites and multilayers" Appl. Phys. B., 2010, 100, 93100.

102. Amin K. A. M.; Panhuis, M. Reinforced materials based on chitosan, $\mathrm{TiO}_{2}$ and $\mathrm{Ag}$ composites. Polymers, 2012, 4, 590-599; doi:10.3390/polym4010590.

103. Chiang, H. P.; Leung P. T.; Tse, W. S. Optical properties of composite materials at high temperatures. Solid State Communications, 1997, Vol. 101 (1), 45-50.

104. Nur-E-Alam, M.; Vasiliev, M.; Alameh, K. Heat Regulating Materials for Energy Savings and Generation," Ch. 4, Central West Publishing Ltd., Australia, in press, 2019.

105. Lee, J. H.; Lee S. H.; Hwangbo, C. K. Optical and structural properties of $\mathrm{TiO}_{2} / \mathrm{Ti} / \mathrm{Ag} / \mathrm{TiO} 2$ and $\mathrm{TiO}_{2} / \mathrm{ITO} / \mathrm{Ag} / \mathrm{ITO} / \mathrm{TiO}_{2}$ metal-dielectric multilayers by RF magnetron sputtering for display application. J. Korean Phys. Soci., 2001, Vol. 44 (3), 750-756.

106. Liu, X.; Cai, X.; Mao J.; Jin, C. ZnS/Ag/ZnS nano-multilayer films for transparent electrodes in flat display application. Appl. Surf. Sci., 2001, 183, 103-110. 